\title{
Silent Scar Dehiscence in Previous Lscs Patients: Six Case Reports Our Experience and Review of Literature
}

\author{
*Krishna Mandade ${ }^{1}$, Shravani Chalasani ${ }^{1}$, Bhavthankar DP ${ }^{2}$, \\ Dr. Sarita deshpande ${ }^{3}$ \\ ${ }^{1}$ Junior resident, Department of OBGY, ${ }^{2}$ Prof \& Head, Department of $O B G Y,{ }^{3}$ Associate proff. OBGY, Rural \\ Medical College, Pravara Institute Of Medical Sciences (DU), Loni, Maharashtra
}

\begin{abstract}
During the second half of 20th century, a cesarean section implied that all subsequent pregnancies were very likely to be delivered in the same way. This policy was the result from the fear of catastrophic uterine scar rupture of

classical cesarean section, which persisted even after its replacement with lower segment cesarean section (LSCS) without the same basis.

Uterine rupture usually occurs at the site of deficient cesarean scars. The majority of fenestrations or dehiscence are asymptomatic and may initially be quite subtle and may be seen during the process of future cesarean sections.

Here we presenting the series of 6 cases of silent scar dehiscence of previous LSCS scar seen during repeat cesarean sections which was apparently accidental finding.

Keywords: Lower Segment Cesarean Section, Vaginal Birth After Cesarean Section, Premature Rupture Of Membrane.
\end{abstract}

\section{Introduction}

Uterine rupture is a rare complication of pregnancy potentially leading to severe maternal and foetal morbidity and mortality. Several risk factors have been identified, the most important being a uterine scar (mostly from previous caesarean) and the use of uterotonic agents for induction of labour. ${ }^{1}$ It is, however, a rare event in Western countries with an estimated incidence of 0.6 per 10,000 live births. ${ }^{1}$

In a WHO systematic review of uterine rupture worldwide, the median incidence was 5.3 per 10,000 births. ${ }^{2}$ The majority of cesarean uterine incisions are low-transverse and this type of incision has the lowest risk for rupture in subsequent pregnancies. ${ }^{3}$ The classical (vertical) scar at the upper part (body) of the uterus is more vulnerable to ruptures and can cause more serious complications both for the mother and her baby (2). ${ }^{3}$

We present here, a series of 6 cases with silent scar dehiscence in previous cesarean section patient without any warning sign, during the month July 2013 to December 2013 in Pravara Rural Hospital, Loni, Maharashtra, India.

Case 1: 25 yrs G2P1L1 40 wks 4 day gestation admitted in Pravara Rural Hospital in view of previous LSCS done at peripheral hospital at Shrirampur with Post date with normal ANC hematological profile and no other high risk factor.

On Examination: pulse 94/min, BP 126/76mmHg. P/A: uterus full term, relaxed, long lie, cephalic with regular fetal heart rate of 140/min. P/V finding: cervix 1 finger dilated, minimally effaced, membranes plus, station high up.

Decision of cesarean section taken in view of Previous LSCS with Post date with Unfavorable cervix. Intra op finding: thinning of previous scar with incomplete rupture noticed.

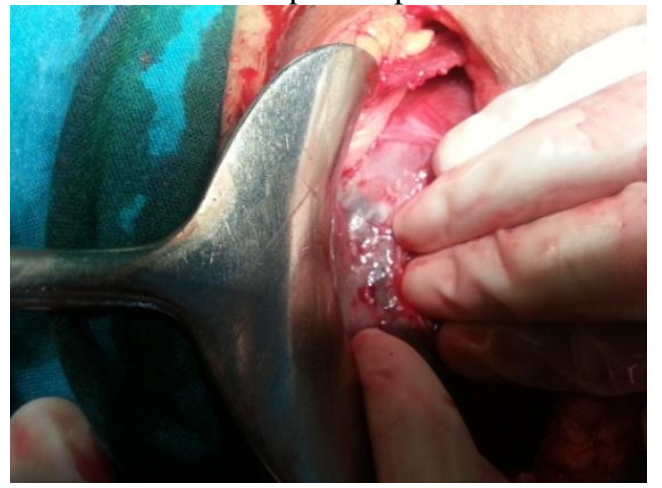




\section{Case 1 Photograph}

Case 2: 23 yrs G3P1L1A1 39 wks 2 day gestation admitted in Pravara Rural Hospital in view of previous LSCS done at peripheral private hospital at Sangamner with severe PIH + Grade 2 protein-urea with normal hematological PIH profile.

On Examination: Pulse 84/min. BP: 150/100mmHg. P/A: uterus full term, relaxed, long lie, cephalic with regular fetal heart rate of $140 / \mathrm{min}$. P/V finding: cervix $1.5 \mathrm{~cm}$ dilated, $50 \%$ effaced, membranes plus, station -3 . Decision of cesarean section taken in view of Previous LSCS with PIH with Unfavorable cervix.

Intra op finding: thinning of previous scar with incomplete rupture noticed.

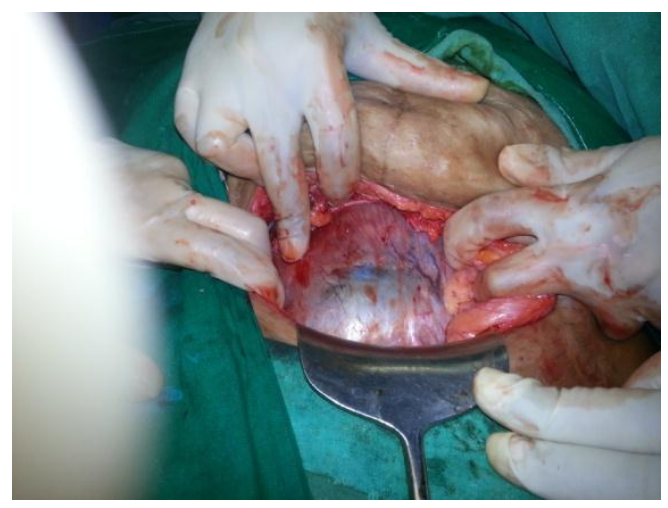

\section{Case 2 Photograph}

Case 3: 21 yrs G2P1L1 40 wks gestation admitted in Pravara Rural Hospital in view of previous LSCS done at peripheral hospital at Shrirampur with complete term with normal ANC hematological profile and no other high risk factor.

On Examination: pulse 90/min, BP 120/70mmHg. P/A: uterus full term, relaxed, long lie, cephalic with regular fetal heart rate of 140/min. P/V finding: cervix 1 finger dilated, minimally effaced, membranes plus, station at 2. Decision of cesarean section taken in view of Previous LSCS with not willing for VBAC. Intra op finding: thinning of previous scar with incomplete rupture noticed.

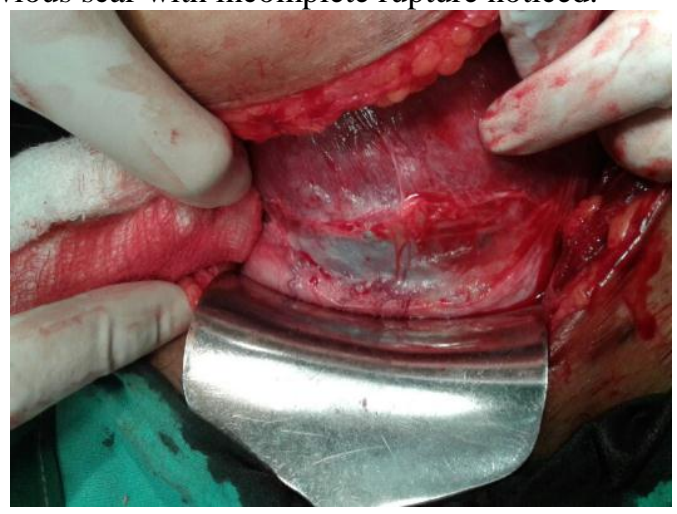

\section{Case 3 Photograph}

Case 4: 27yrs G4P1L1A2 37 wks gestation admitted in Pravara Rural Hospital in view of previous LSCS done at peripheral private hospital at Shirdi with breech presentation with normal ANC hematological profile and no other high risk factor.

On Examination: pulse 80/min, BP 122/70mmHg. P/A: uterus full term, palpable contractions present, long lie, breech presentation with regular fetal heart rate of 140/min. P/V finding: cervix $4 \mathrm{~cm}$ dilated, $70 \%$ effaced, membranes plus, station at -2 . Decision of cesarean section taken in view of Previous LSCS with breech presentation in labour.

Intra op finding: thinning of previous scar with incomplete rupture noticed. 


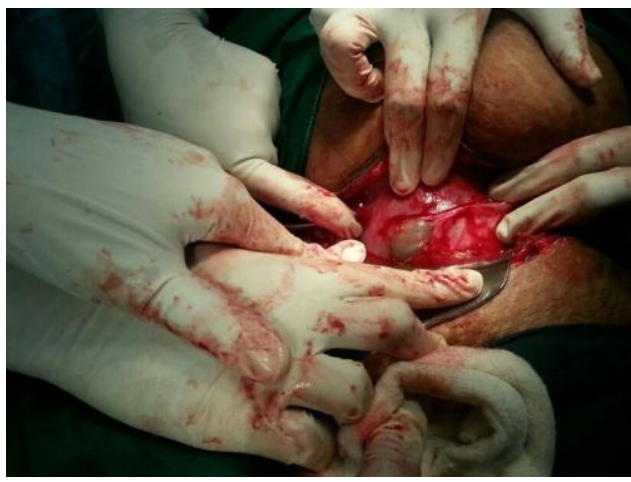

\section{Case 4 Photograph}

Case 5: 22yrs G2P1L1 38 wks gestation admitted in Pravara Rural Hospital in view of previous LSCS done at peripheral hospital at Rahuri with PROM since 4hrs with normal ANC hematological profile and no other high risk factor.

On Examination: pulse 90/min, BP 130/80 mmHg. P/A: uterus full term, palpable contractions present, long lie, cephalic with regular fetal heart rate of 140/min. P/V finding: cervix 1 finger dilated, minimally effaced, membranes absent, station at -2 . Decision of cesarean section taken in view of Previous LSCS with PROM. Intra op finding: thinning of previous scar with incomplete rupture noticed.

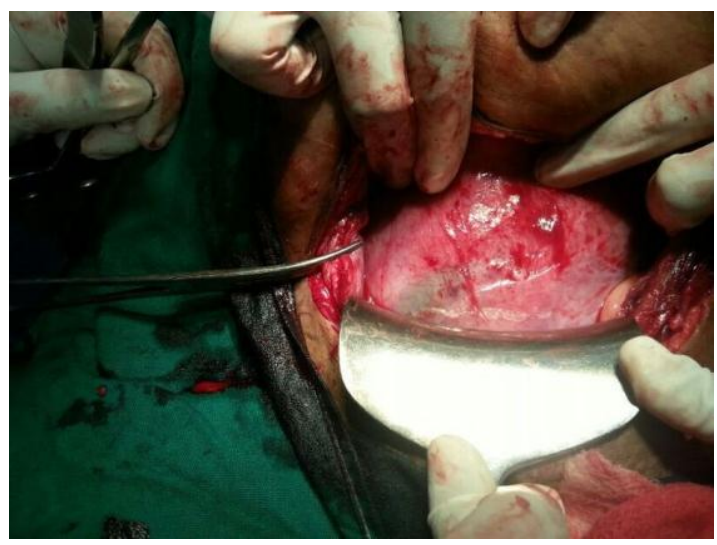

\section{Case 5 Photograph}

Case 6: 24yrs G2P1L1 38 wks gestation admitted in Pravara Rural Hospital in view of previous LSCS done at Pravara Rural Hospital with oligohydramnios (AFI $2 \mathrm{~cm}$ ) with normal ANC hematological profile and no other high risk factor.

On Examination: pulse 88/min, BP 112/60mmHg. P/A: uterus full term, relaxed, long lie, breech presentation with regular fetal heart rate of 140/min. P/V finding: cervix closed, uneffaced, station at high up. Decision of cesarean section taken in view of Previous LSCS with severe oligohydramnios.

Intra op finding: thinning of previous scar with incomplete rupture noticed.

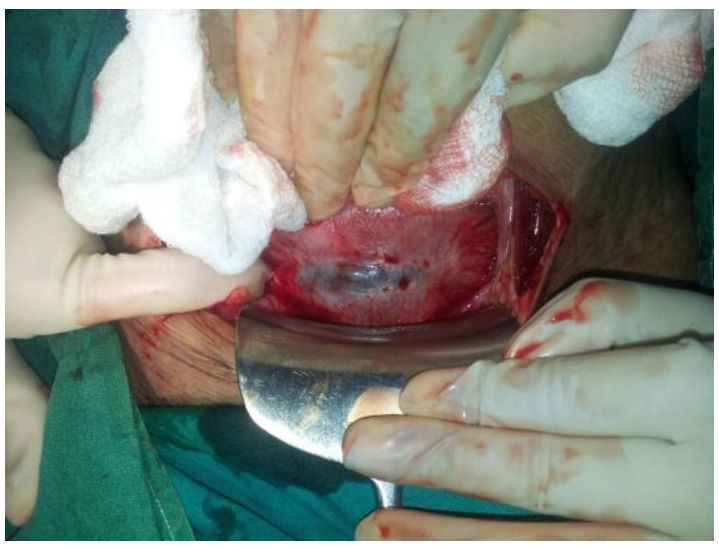

\section{Case 6 Photograph}




\section{Discussion}

The risk of scar dehiscence in the presence of a defective scar is related to the degree of thinning of the lower uterine segment. In our observation incidence of scar dehiscence was found in $34.2 \%$ of the patients in which week scar was expected on the basis of warning sign like scar tenderness in our hospital on other hand $4.1 \%$ of the patients found with unexpected, unwarned scar dehiscence among previously scared uterus. If the overlying myometrium is thinner, the risk of the above mentioned complications in subsequent pregnancies are higher. ${ }^{4}$

Uterine rupture typically is classified as either:

1) Complete uterine rupture was defined as complete

when all layers of the uterine wall are separated, with

or without expulsion of the fetus or 2) Incomplete uterine

rupture was defined as incomplete when the uterine

muscle is separated but the visceral peritoneum is intact(dehiscence) ${ }^{5}$

A complete uterine rupture cannot usually be predicted and it will suddenly occur during labor or delivery. Termination of pregnancy should be considered if any sudden pain is present. Several concomitant symptoms of eminent uterine rupture include vaginal bleeding, sharp pain between contractions, abdominal pain or tenderness,

recession of the fetal head, bulging under the pubic bone (baby's head protrudes out of the uterine scar), and scar tenderness. ${ }^{6,7}$

In our case series these concomitant symptoms of eminent uterine rupture were absent and incomplete scar dehiscence was accidental finding which is suggestive of unexplained prediction of scar.

Clinical judgment of integrity of scar is highly unpredictable.

\section{Conclusion}

We believe that though the uterine ruptures have definitive predictive signs, many times they may be unpredictable.

In spite of advanced feto-maternal monitoring techniques, incomplete scar rupture may be missed.

Scar dehiscence may also be present without concomitant symptoms and signs.

Before opting for VBAC delivery, we must keep in mind that 'surprises are always there for us' but 'we must be aware of it!'

\section{References}

[1]. Guise JM, McDonagh MS, Osterweil P, Nygren P, Chan BK, Helfand M. Systematic review of the incidence and consequences of uterine rupture in women with previous caesarean section. BMJ 2004;329:19-25.

[2]. Hofmeyr GJ, Say L, Gulmezoglu AM. WHO systematic review of maternal mortality and morbidity: the prevalence of uterine rupture. BJOG 2005;112:1221-8.

[3]. Jastrow N, Chaillet N, Roberge S, Morency AM, Lacasse Y, Bujold E. Sonographic lower uterine segment thickness and risk of uterine scar defect: a systematic review. J Obstet Gynaecol Can. 2010;32(4):321-7.

[4]. Rozenberg P, Goffinet F, Phillippe HJ, Nisand I. Ultrasonographic measurement of lower uterine segment to assess risk of defects of scarred uterus. Lancet.1996;347(8997):281-4.

[5]. Cunningham FG, Leveno KJ, Bloom SL, Hauth JC, Rouse DJ, Spong CY. Prior cesarean delivery. In: Williams Obstetrics edited by Cunningham FG, Leveno KJ, Bloom SL, Hauth JC, Rouse DJ, Spong CY. 23st edn. New York: Mc Graw-Hill. 2010

[6]. Arulkumaran S, Chua S, Ratnam SS. Symptoms and signs with scar rupture--value of uterine activity measurements. Aust N Z J Obstet Gynaecol. 1992; 32(3):208-12.

[7]. Gotoh H, Masuzaki H, Yoshida A, Yoshimura S, Miyamura T, Ishimaru T. Predicting incomplete uterine rupture with vaginal sonography during the late second trimester in women with prior cesarean. Obstet Gynecol. 2000;95(4):596-600. 